\title{
Practices and Perspectives on Mental Health in the Balkan Countries: A Narrative Review
}

\author{
Maya E. Lee \\ Faculty Mentor: Marina Antić, Department of Slavic and East European Languages and Cultures, Indiana \\ University Bloomington
}

\begin{abstract}
Mental health and wellness are integral parts to a person's overall health and happiness, leading to an increased initiative to treat and support people living with mental health problems. A literary review researching the background of mental health treatment and how it intersects with the unique history and current situations within the former Yugoslav Republic nations was conducted. Existing literature about mental healthcare prevalence and practices within the region was analyzed and contextualized with regards to these historical perspectives. Significant gaps in research literature were identified, including economic research that is needed to determine how and from which governing body national healthcare systems should be funded. There is also a need for standardized data collection about where mental health infrastructure exists within the region and how effective its treatments are for patients. Finally, increased research into everyday mental disorders that are unrelated to the recent civil war would create accurate data for treatments and policies to better reflect the needs of the people. Filling these lapses in knowledge would greatly reduce barriers to mental healthcare within the Balkans.
\end{abstract}

KEYWORDS: mental health, Balkans, Eastern Europe, healthcare systems

\section{INTRODUCTION}

$\mathrm{M}$

ental disorders and diseases impact the lives of those who suffer from them as well as their loved ones across the world. Mental health and wellness practices are of significant importance to regaining and/or maintaining a healthy and happy lifestyle. In this review, the current state of mental healthcare within the Balkan countries is analyzed. This evaluation is contextualized within a history of mental healthcare practices and a history of the Balkans. The methodology consists of an overview of existing research on the state of mental healthcare services in the Balkans, with focus on the post-Communist period. Review of this literature and most recent data leads us to conclude that there exists significant barriers to effective mental healthcare services in the Balkans, but that they are not due to cultural or historical reasons (as has been frequently claimed in the past) but rather financial, governmental, and administrative obstacles that diminish the accessibility and efficacy of mental healthcare, not unlike elsewhere in the world.

\section{HISTORY OF MENTAL HEALTH AND WELLNESS}

Training in psychological and/or psychiatric health and treatments are crucial components of healthcare provision. However, this was not always the case. Throughout the last century, both the perceptions and practices of what is now encompassed by the term "mental health" have changed drastically for many reasons. When analyzed from a global viewpoint, this evolution follows a detectable trend from institution-centered treatments to more modern patient-focused care that emphasizes managing symptoms while maintaining a patient's quality of life and independence.

Around the start of the twentieth century, global attitudes to mental illness changed drastically, shifting the perspective of mental ailments away from social deviance or moral shortcomings with religious undertones (Bassuk and Gerson, 1978) and towards the more medical model we know today (i.e., as illnesses that require treatment). Even more recently in the last forty years, many nations have seen a shift from psychosocial to biopsychosocial models of explaining and treating mental illness (Drake et al., 2003). This new approach aims not only to mitigate the symptoms of a mental disorder, but also to ensure that patients can live autonomously and be contributing members of society.

Alongside these changes in how we understand the causes of mental disorders, we have seen changes in how these symptoms are treated. The institutionalization of the mentally ill grew in popularity and practice, and was thought to provide an avenue to "protect [others in] society" from the mentally unwell (Bassuk and Gerson, 1978, p. 46). However, throughout the twentieth century, nations have seen marked deinstitutionalization in mental health treatments, highlighting the trend to treat patients and their illnesses in the hopes of societal reintegration, not simply sequestering them into institutions. For example, in post-WWII England, this change involved the closing of large insane asylums in the 1960s, as well as its National Health Service acknowledging mental illness as a prominent problem and incorporating mental health treatments into general medical practices (Turner et al., 2015).

At the close of the twentieth century we have seen increased focus on mental health globally, as exemplified by the publication of United Nations guidelines for governments around the world that provided increased rights to people dealing with mental health issues and their families in 1991 (World Health Organization, 2002). Since then, many global health institutions such as the World Health Organization have made mental health a priority by forming the Nationals for Mental Health coalition in 1996, which jumpstarted mental health initiatives across Europe, Africa, and Asia. Likewise, the 1993 report released by the World Bank identified that up to $8 \%$ of the "global financial burden of disability and disease" in the world is due to mental health-related issues. Statistics and international efforts such as these have led to increased awareness of mental health problems, encouraging governing bodies (whether nationwide or international) to become more involved in the advancement of mental health treatment and rehabilitation.

This paper seeks to analyze the current state of mental wellness within the Balkans. The presence or lack of research and knowledge concerning the state of healthcare within each country, and any consequential challenges those may have on mental health treatment in that nation, are here evaluated through a historical lens. 


\section{HISTORY OF MENTAL HEALTH AND WELLNESS IN THE BALKANS}

In order to thoroughly understand the current state of mental healthcare and its practices within this region, we must examine the checkered history of psychology and psychiatry in relation to peripheral spaces in the world, the Balkans in particular. The exoticization of the area, with its roots dating back to the postEnlightenment era, created a discourse that defined stereotypes surrounding the region and its inhabitants, affecting how psychology and psychiatry interacted with the Balkans and its peoples (Bjelić, 2010). In the 20th century, the Cold War further cemented some of these stereotypes by propagating the Western belief that the research, practice, and treatment of mental health diseases were greatly hindered due to Communist rule (Savelli and Marks, 2015). As this review will show, any research into the region's mental healthcare must take into account this history and beware of reproducing stereotypes.

More recently, the wars of Yugoslav succession have impacted mental health research in Balkan nations dramatically. The postCommunist development of each country has had lasting impact on the state of mental wellness in the region. High incidence of warrelated mental trauma and its after-effects have been the major foci of mental health research within the region. But, even more fundamentally, the wars and post-war developments have proven financially and administratively challenging, contributing to the burden of funding necessary treatments or programming (Tomov, 2001).

\section{Balkans as the Exotic Other}

The region of southeastern Europe classified as the Balkans has varying boundaries and definitions. More modernly, the term has become associated with the countries which once made up the Yugoslav Republic: Bosnia and Herzegovina, Croatia, Macedonia, Montenegro, Serbia, and Slovenia. This geopolitical definition acquired a negative connotation after the Balkan Wars (both at the beginning and end of the 20th century), eventually giving rise to the term "balkanization," meaning to break into smaller regions or states that are often hostile or uncooperative with one another (Bjelić, 2010, p. 84). In his article "Mad Country, Mad Psychiatrists: Psychoanalysis and the Balkan Genocide," Dušan Bjelić (2010) summarizes the historical foundations for the modern state of mental illness within the Balkans, in regard to both psychology and the war of Yugoslav succession during the late 1990s. Bjelic argues that the region has been perceived as distinct from the rest of Europe for reasons dating back to the post-Enlightenment era. After the onset of this new way of thinking (which originated in Western Europe) in the eighteenth century, Eastern Europe was type-casted as the geopolitical Other, a land full of barbarism and backwards thinking whose people were not capable of following modern thought. Indeed, the term "balkanization" carried pejorative connotations and became "a synonym for the reversion to the tribal, the backward, the primitive, the barbarian” (Todorova, 2009, p. 3).

It is important to beware of the tendency to marginalize and Orientalize the Balkans when evaluating the history and practice of mental health and wellness. In other words, claims of Balkan backwardness or imperfect mental health practices must be checked against this prevailing history of marginalization and stereotyping, as these dialogues seem to have affected the scholarship on the contemporary state of Balkan mental health.

\section{Legacies of the Cold War}

Larry Wolff (1994) notes that the so-called Iron Curtain happened to fall along the demarcation of Europe that dated back to the Enlightenment ideas of the civilized West countered by the barbaric East. Indeed, even after the downfall of the Iron Curtain, the concept of Eastern Europe and its role as the dark counterpart to the more modern West has prevailed and impacted the dialogue surrounding ideas about health produced from this region. Wolff argues that beyond the delineations of the former Communist bloc, the West has "passively inherited" the idea of Eastern Europe that was conceived centuries prior, affecting opinions of the modernity of the region and reinforcing stereotypes of its peoples as backwards (Wolff, 1994, p. 3).

The Cold War resulted in multiple economic sanctions and the restriction of exports to Eastern bloc countries, including the Balkans. Western scholars and authors have theorized that this period led the then-Communist countries that now comprise the Balkans to fall behind in not only mental healthcare, but also overall healthcare and infrastructure. This "legacy of communism" is purported to have led to the lag in technological advances and governmental healthcare reform that was so formative for Western systems during this time (Tomov, 2001, p. 12). Additionally, Western researchers speculate that the destabilization caused by the collapse of the Communist bloc and the former Yugoslav Republic further contributed to the lack of healthcare policy and reform within these post-totalitarian countries (Jenkins et al., 2005).

However, recent research contradicts these conclusions. Savelli and Marks demonstrate that in the fields of psychology and clinical psychiatry, there was collaboration and participation from "both sides of the Iron Curtain" (Savelli and Marks, 2015, p. 125). Evidence for this can be noted from the historical regional collaboration between then-Communist countries and other nations, including multiple conferences and scientific articles. For example, Eastern bloc research was presented in Western countries during Communist rule. Likewise, research originating in Eastern-bloc countries also influenced scientific developments in the West. Examples include an approach to the clinical treatment of alcoholism, requiring a shift from viewing it as a personal problem to a certifiable illness, which was developed in Yugoslavia during the 1960s. Moreover, the Pavlovian theory that mental illnesses are derived from abnormal cortical structures (Savelli, 2018) serves as another instance of Eastern Europe influencing the West. Both concepts were eventually accepted globally and align with the worldwide trend towards the aforementioned biopsychosocial approach to treating mental illness.

The oversimplified assumption that all Communist countries operated in the same fashion as the Soviet Union, Savelli argues, led to the permeating Western belief that psychiatry under the Communist regime was "inextricably bound" to socialist ideologies (Savelli, 2018). This belief is challenged by noting that psychiatry in Yugoslavia was able to be uniquely influenced by Western European, American, and socialist principles due to Yugoslavia's political break from Staliniststyle Communism in 1948 (Antić, 2016).

\section{Wars of Yugoslav Succession}

Beyond the geopolitical discourse that distinguished the Balkans from the rest of Europe, its current grappling with the after-effects of the recent civil war has also uniquely challenged the region. The war, leading to the breakup of the Yugoslav Republic into separate, smaller countries, dominates current discussion about mental health and wellness within the region, specifically regarding post-traumatic stress disorder (PTSD). The amount of research solely dedicated to investigating the incidence of PTSD in the Balkans may attest to the severity of the conflict. According to Susan Woodward (1995), the 
conflict generated the largest refugee crisis in Europe since World War II (p. 2) and warranted the first deployment of NATO troops to a European country (p. 3). Furthermore, the economic costs of the War and the infrastructure lost during that time created a notable financial burden that is perhaps not unrelated to the paucity of funding of healthcare systems and wellness programming. The reorganization and/or founding of new governing bodies post-war, research shows, has also contributed to lapses in availability and access to some healthcare (Tomov, 2001).

While the wars of Yugoslav succession may dictate many of the topics surrounding current mental healthcare and wellness, it is important to be cognizant of the broader history and take care to not repeat the past mistakes of over-emphasizing the otherness of the region. It is necessary to recognize that these histories have impacted health and wellness today by influencing how research into mental health from the region is done and contextualized (i.e., almost exclusive investigation of post-war conditions and PTSD). In addition to the significant funding difficulties and out-of-pocket payments to treat somatic diseases (see demographic research section), there is a chance that mental health issues may be even more threatened to be ignored due to significant stigma surrounding these problems and a lack of current available resources and treatments (Tirintica et al., 2018). When taken together, these barriers to healthcare impose a great risk to the overall mental wellbeing of Balkan peoples.

\section{CURRENT STATE OF MENTAL HEALTH AND WELLNESS RESEARCH IN THE BALKANS}

In the following section, an overview of the current state of research into mental healthcare and wellness in the region is presented. Existing research can be divided into three major areas: quantitative studies of the prevalence of specific disorders, research into the state of policies affecting mental health and wellness, and broader research into healthcare systems and delivery that affect mental healthcare. Major findings within each of these areas are here outlined.

A significant portion of current demographic research conducted about the region deals with how mental health was affected by the war in the 1990s. Other sociological and survey research has attempted to investigate the conditions of mental/overall healthcare access and management within the region. These assessments are used to evaluate the efficacy and delivery of healthcare in the Balkan nations and the threats or barriers to accessing better quality care that still exist.

\section{A Review of Current Mental Health Demographic Data in the Balkans}

To date, recent studies and surveys have shown that PTSD, along with major depressive disorder (MDD), are widespread within the region. In a survey study conducted in Serbia, $48 \%$ of respondents self-described their mental health status as "poor," with $4.9 \%$ of respondents having been diagnosed with chronic depression (Sanrić-Miličević et al., 2016, p. 36). In Croatia, risk factors for the development of both PTSD and MDD have been researched, finding that increased minority status within society (e.g., ethnic or gender minority, lower socioeconomic statues, etc.) increased the risk of developing PTSD. In particular, women were found to be at increased risk due to decreased political and economic autonomy following the demise of socialism after the war, as well as the widespread use of rape as a weapon during the war (Kunovich and Hodson, 1999, p. 325). A study conducted with refugees who had survived the war while living in what is now Bosnia and Herzegovina found that exposure to war experiences and incidence of human rights violations (as defined by the Geneva Convention) increased the risk of developing PTSD. Within the studied cohort of thousands of Bosnian survivors, 30\% were diagnosed with PTSD and $28 \%$ with MDD. The most commonly cited war experience amongst respondents was "active shelling/bombardment" (more than 70\%) (Priebe et al., 2010, p. 2172). A study of Sarajevan school-aged children found that war exposure (here defined as witnessing killings and/or dead bodies or surviving bombings) increased the risk of developing PTSD. PTSD was also found to be comorbid with the presentation of Attention Deficit Disorder symptomatology at a rate equivalent to that of the global population (Husein et al., 2008). Furthermore, a study analyzing sensitivity to glucocorticoids, which are hormones released during times of stress, and its relation to PTSD diagnosis amongst Bosnian war refugees and control German citizens who had not been exposed to the Balkan War found that participants who had been diagnosed with PTSD were more sensitive to glucocorticoids (Pitts et al., 2016). While there is ample research investigating postwar mental illness in the region, there is a need for more inquiries into mental healthcare and wellness in the Balkans as it pertains to the everyday person or patient.

\section{State of Mental Health and Wellness Policies}

Research reviewed here indicates there is a need for mental wellness programming and treatment in the Balkans. However, varying policies and institutions within former Yugoslav nations affect the availability and accessibility of interventions. While these studies and their findings are impactful, it is difficult to parcel out specific effects that the recent wars have had on each individual country. The breakup of the former Yugoslav Republic was not uniform, and individual differences between these countries can be seen post-war in their policies and preparedness to combat the lasting effects of mental illness in the region (Jakovljević, 2013).

Countries within the region lack effective national bodies that are dedicated to mental illness awareness, prevention, and treatment. While some Balkan nations have established such entities, inadequate implementation of its policies weaken their efficacy. Other countries lack such bodies altogether. For example, an assessment found that in Croatia, the process of deinstitutionalization of mental illness facilities started in the early 1990s - significantly earlier than what is observed in other Balkan states (Mihić et al., 2015). This difference is theorized to be accounted for by various factors: Croatia's pro-European stance during a time when the nation was vying for European Union entry (Mihić et al., 2015), the application of international trauma programs after the war to alleviate mental illness and trauma (Pupavać and Pupavać, 2012), and the fact that Croatia has the highest average annual income of any other Balkan nation (Jakovljević, 2013). It is also the only Balkan country to have certified and trained Health Technology Assessments (HTA), a systematic approach that helps make informed decisions of health budgeting and technologies. However, even with these advantages, Croatia still suffers from the lack of organization and implementation of mental health policies at the governmental level, making effectual treatment more difficult.

The Former Yugoslav Republic of Macedonia has also observed deinstitutionalization and the downsizing of psychiatric facilities in favor of more community-based mental health services. Moreover, it officially established a National Mental Health Policy in 2005 (Manuševa et al., 2016) and employs HTA training and guidelines. Serbia was slower to follow global trends in deinstitutionalization. Its current healthcare system (a mix between private and socialized) is suffering major economic losses, having yet to develop a costconscious policy (Jakovljević, 2013). On the other hand, Bosnia and Herzegovina has developed but not implemented a cost-effective budgeting system for their healthcare and lacks HTA training and 
programming. According to the same study, Montenegro's healthcare system has the highest per capita spending out of all of the Balkan nations, but is also suffering funding issues due to ineffective policies. Kosovo has no national health insurance fund, and access to treatment of mental illnesses is limited.

With varying degrees of established infrastructure and government support, it becomes difficult to compare the state of mental healthcare in each Balkan nation. Additionally, various systems that track health and/or research information exist in each country, making data nonuniform across nations.

\section{Healthcare Delivery in the Balkans}

As a subsidiary of overall health, mental health is inextricably affected by current policies and the access to/availability of treatments, medications, etc. Below is a brief summary of healthcare systems and practices within former Yugoslav nations, as well as issues within these systems that could prove to be barriers to overall and mental healthcare.

Each country is threatened by the volatility of their single-payer healthcare funding systems. Socialized systems as seen in Serbia, Bosnia and Herzegovina, Macedonia, Montenegro, and (to a lesser degree) Croatia are extremely precarious when placed in the context of recovering from a series of larger economic setbacks since the wars of Yugoslav succession. For example, in the case of Serbia, notable dips in funding and thus healthcare coverage were seen during the 1990s because of the war, and again in 2008 due to the worldwide recession (Jankovljević, 2013). In an effort to curb spending, the Serbian National Health Institute established multiple policies and pharmaceutical guidelines in 2011 and instructed healthcare providers to limit resource consumption. However, in a nationwide survey conducted with primary, secondary, private, and specialist healthcare providers, it was shown that providers either remained largely unaware of the cost-cutting measures they were supposed to be taking part in, or they perceived the measures to decrease the quality of care they were able to administer. Consequently, the government's policies, while existent, were largely ignored and left unimplemented (Jankovljević, 2013).

The problem of healthcare system funding is not a new one to the region, with many solutions attempting to be applied. Funding healthcare systems via taxation, which is commonplace in Europe, can have reduced effectiveness in the Balkans due to high unemployment rates, unreported employment, increased corruption, and unpaid labor (Bredenkamp et al., 2013). For example, the current system used in Serbia allows for a population (making up approximately $16 \%$ of the entire populace) of patients that are supposedly exempt from paying expenses for their health coverage (Arsenijević et al., 2013, p. 374). However, yet again, coverage is lost in the intricacies of applying these rules: there are no laws stating private practices must abide by exemption rules, the guidelines for what qualifies a patient to be exempt are ambiguous and not known by providers nationwide, the process to file for exemption is convoluted, and there is a noted social stigma against identifying as a person of an exempt population (Arsenijević et al., 2013). All of these difficulties create barriers to care and health coverage for the people of Serbia.

Additionally, the practice of informal payments in exchange for healthcare or higher quality of care is widely practiced throughout the Balkans and continues to produce even further disparities (Bredenkamp et al., 2013). In a survey conducted throughout the region, it was found that $50 \%$ of Kosovars, $42 \%$ of Bosnians, and $22 \%$ of Serbs and Montenegrins paid out-of-pocket informal payments (Bredenkamp et al., 2013, p. 349). These informal payments, in the forms of gifts, foods, jewelry, or other services, may also include "bought and brought goods." These are defined as payments for goods or the expectation that the patient provides goods that are required for care and which should be covered by health insurance (Mejsner and Karlsson, 2017, p. 621). Indeed, some respondents to a study conducted throughout the region stated that they either were unaware that the payments they were being asked to provide were informal/should be covered by their insurance, or they were seen as the only way to receive better quality care. Furthermore, these types of out-of-pocket payments were shown to be correlated with peoples' vulnerability to poverty, and healthcare expenditures made up a large portion of Balkanites' total expenses (Bredenkamp et al., 2013).

\section{FUTURE DIRECTIONS}

In conclusion, while the perceptions of mental health are influenced by the historical geopolitical discourse that surrounds the region, disparities in the accessibility and quality of mental healthcare within the Balkans are in fact due to far-reaching governmental, financial, and administrative obstacles. It is worth reemphasizing that the trend of treating mental illness as a disease that necessitates medical intervention instead of a personal problem has been seen both globally and within the Balkans. However, while the region has been on par with the global community in terms of perceptions and theories, the issues of actual delivery and implementation of these practices still remain.

Through cultural and historical analysis, it has been determined that many problems exist within the healthcare system related to mental health and wellness treatment within the Balkans. In order for these barriers to be abated, these specific gaps in knowledge must be addressed: which governing bodies should be in charge of funding healthcare systems so that free, nationwide coverage is actualized; mental healthcare infrastructure already in place and their effectiveness; and the impact of everyday mental illness (outside of post-war research) on people living in the Balkans.

These inquiries will require interactive, research-based efforts between each nation's mental healthcare providers and their healthcare system(s). Research should be conducted at the federal and hospital levels. Within the governments of each nation, research is necessary to identify where healthcare funding should come from and how/where financial income should best be allocated to optimize coverage. Furthermore, economic interventions such as increasing trainings (e.g., HTA) and resource-saving programming that is both widely known and amenable to practicing medicine would improve the cost efficacy of providing healthcare. At the hospital level, systematic reviews of what mental wellness care is available would help ensure that coverage is not localized to only certain areas of the country and is reaching as many people as possible. Likewise, quality assessments within both public and private clinical settings regarding the efficacy of pre-existing care will continue to improve each country's health outcomes. The standardization of this collected data would facilitate the sharing of information within and between nations, possibly lending to further collaboration and support for treatment efforts. Finally, more research outside of the realms of post-war PTSD and/ or MDD could improve the average person's mental health. With this gain of knowledge, treatments and programming would be specifically catered to effectively address the needs of the people within each nation. All of these changes would bridge the divide between the development of policies and the implementation of medical treatments to ensure people and patients within the Balkans have equitable access to care and thus better health outcomes.

\section{ACKNOWLEDGMENTS}

The author would like to thank professor Marina Antic of the Slavic and Eastern European Languages and Cultures program at Indiana 
University. Without her tireless support and encouragement, the above text would never have been able to be written, much less published. Hvala ti, Marina!

\section{AUTHOR INFORMATION}

All correspondence should be sent to the first author: mayalee913@gmail.com

\section{REFERENCES}

Antić, A. (2016). The pedagogy of worker's self-management: terror, therapy, and reform communism in Yugoslavia after the Tito-Stalin split. Journal of Social History, 50(1), 179-203.

Arsenijević, J., Paplova, M., Groot, W. (2014). Out-of-pocket payments for public healthcare services by selected exempted groups in Serbia during period of post-war healthcare reforms. International Journal of Health Planning and Management, 29, 373-398.

Bassuk, E., \& Gerson, S. (1978). Deinstitutionalization and mental health services. Scientific American, 238(2), 46-53.

Bjelić, D. (2010). Mad country, mad psychiatrists: Psychoanalysis and the Balkan Genocide. In Freud and fundamentalism: the psychical politics of knowledge (pp. 83-104). New York: Fordham University Press

Bredenkamp, C., Mendola, M., \& Gragnolati, M. (2011). Catastrophic and impoverishing effects of health expenditure: New evidence from the Western Balkans. Health Policy and Planning, 26, 349-356.

Husain, S. A., Allwood, M., \& Bell, D. (2008). The relationship between PTSD symptoms and attention problems in children exposed to the Bosnian War. Journal of Emotional and Behavioral Disorders, 16(1), 52-62.

Jakovljević, M. (2013). Resource allocation strategies in Southeastern European health policy. The European Journal of Health Economics, 14(2), 153-159.

Kunovich, R., \& Hodson, R. (1999). Civil war, social integration, and mental health in Croatia, Journal of Health and Social Behavior, 40(4), 323-343.

Manuševa, N., Arsova, S., Markovska-Simoska, S., Novotni, A., Stefanovski, B., \& Raleva, M. (2016). Mental health legislation and involuntary hospitalization in the Republic of Macedonia. Macedonian Journal of Medical Sciences, 4(3), 458-460.

Mejsner, S. B., \& Karlsson, L. E. (2017). Informal patient payments and bought brought goods in the Western Balkans - A scoping review. International Journal of Health Policy and Management, 6(11), 621-637.
Mihić, J., Novak, M., Hosman, C., \& Domitrovich, C. (2017). Assessing quality of mental health promotion and prevention in Croatia: the case of Istria. Health Promotion International, 32, 511-521.

Pitts, K., Joksimović, L., Steudte-Schmiedgen, S., Rohleder, N., \& Wolf, J. (2016). Determinants of altered intracellular endocrineimmune interplay in Bosnian War refugees suffering from PTSD. Biological Psychology, 118, 1-7.

Priebe, S., Bogić, M., Ashcroft, R., Francisković, T., Galeazzi, G. M., Kucukalic, A., Lečić-Tosevski, D., Morina, N., Popovski, M., Roughton, M., Schützwohl, M., \& Ajduković, D. (2010). Experience of human rights violations and subsequent mental disorders - A study following war in the Balkans. Social Science \& Medicine, 71, 2170-2177.

Pupavać, M., \& Pupavać, V. (2012). Trauma, advocacy, veteran politics, and the Croatian therapeutic state. Alternatives: Global, Local, Political, 37(3), 199-213.

Savelli, M. (2018). Beyond ideological platitudes: socialism and psychiatry in Eastern Europe. Palgrave communications, 4(45).

Savelli, M., \& Marks, S. (2015). Psychiatry in Communist Europe. England, UK: Palgrave Macmillan.

Tirintica, AR., Andjelković, I., Sota, O., Pirlog, MC., Stoyanova, M., Mihai, A., \& Wallance, N. (2018). Factors that influence access to mental health services in South-Eastern Europe. International Journal of Mental Health Systems, 12(1).

Todorova, M. (2010). Imagining the Balkans. England, UK: Oxford University Press.

Tomov, T. (2001). Mental health reforms in Eastern Europe. Acta Psychiatrica Scandinavica, 104(410), 2126.

Turner, J. Hayward, R., Angel, K., Fulford, B., Hall, J., Millard, C., \& Thomson, M. The history of mental health services in modern England: Practitioner memories and directions for future research. Medical History, 59(4), 599-624.

Wolff, L. (1994). Inventing Eastern Europe: The Map of Civilization on the Mind of the Enlightenment. Stanford: Stanford University Press.

Woodward, S. L. (1995). Balkan Tragedy: Chaos and Dissolution After the Cold War. Massachusetts, USA: The Brookings Institution.

World Health Organization. (2002). Nations report for mental health. 
